\title{
PAMs inhibits monoamine oxidase a activity and reduces glioma tumor growth, a potential adjuvant treatment for glioma
}

Pei-Chuan Li ${ }^{1,2+}$, Shih-Yi Chen ${ }^{1,2,3 \dagger}$, Danzhou Xiangfei ${ }^{4}$, Canquan Mao ${ }^{5}$, Chieh-His Wu ${ }^{3}$ and Jean Chen Shih ${ }^{1,2,6,7^{*}}$

\begin{abstract}
Background: Monoamine oxidase (MAO) A catalyzes oxidative deamination of monoamine neurotransmitters and dietary amines and regulates brain development and functions. Recently, we showed that MAO A mediates the progression and migration of glioma and MAO A inhibitors reduce glioma cell growth. Glioblastoma (GBM) is a common and most malignant brain tumor which is difficult to treat. Temozolomide (TMZ) is the current standard chemotherapy for glioma, but tumors usually become resistant and recur. So far, no effective therapy for TMZresistant glioma is available. Natural plant antimicrobial solution (PAMs) is a Chinese herbal medicine which has been used for decades without toxicity and has multiple medical functions including anti- inflammatory effects. Here, we report the effects of PAMs on glioblastoma growth.
\end{abstract}

Methods: The growth of TMZ -sensitive (U251S),-resistant (U251R) human glioma cells, and mouse glioma cell line GL-26 were assessed by MTS colorimetric assay, colony formation, and cell migration assays.

Male C57BL/6 mice were implanted subcutaneously or intracranial with luciferase-positive mouse glioma GL-26 cells and treated with vehicle; MAO A inhibitor clorgyline (10 mg/kg); TMZ (1 mg/kg); PAMs (48 mg/kg) alone or in combination with TMZ (1 mg/kg) for 14 days. At the end of the treatment, mice were sacrificed, MAO A catalytic activity in tumors was measured, and tumor sizes were determined by imaging and weight.

Results: These results show that PAMs inhibits MAO A catalytic activity in all three glioma cell lines studied U251S, U251R, and GL-26. PAMs reduced glioma growth and has greater effects in combination with low dose of TMZ than PAMS or TMZ alone in all three cell lines as shown by MTS, colony formation, and cell migration assays. Using the subcutaneous or intracranial GL-26 glioma mouse model, PAMs reduced the tumor growth and MAO A activity, similar to the MAO A inhibitor clorgyline. Combining PAMs with non-toxic dose TMZ increased survival to a greater extent than those of PAMs or TMZ alone.

(Continued on next page)

\footnotetext{
* Correspondence: jcshih@usc.edu

${ }^{\dagger}$ Pei-Chuan Li and Shih-Yi Chen contributed equally to this work.

'Department of Pharmacology and Pharmaceutical Sciences, School of

Pharmacy, University of Southern California, Rm. 518, 1985 Zonal Ave, Los

Angeles, CA 90089, USA

USC-Taiwan Center for Translational Research, School of Pharmacy,

University of Southern California, Los Angeles, CA 90089, USA

Full list of author information is available at the end of the article
}

(C) The Author(s). 2020 Open Access This article is licensed under a Creative Commons Attribution 4.0 International License, which permits use, sharing, adaptation, distribution and reproduction in any medium or format, as long as you give appropriate credit to the original author(s) and the source, provide a link to the Creative Commons licence, and indicate if changes were made. The images or other third party material in this article are included in the article's Creative Commons licence, unless indicated otherwise in a credit line to the material. If material is not included in the article's Creative Commons licence and your intended use is not permitted by statutory regulation or exceeds the permitted use, you will need to obtain permission directly from the copyright holder. To view a copy of this licence, visit http://creativecommons.org/licenses/by/4.0/. The Creative Commons Public Domain Dedication waiver (http://creativecommons.org/publicdomain/zero/1.0/) applies to the data made available in this article, unless otherwise stated in a credit line to the data. 
(Continued from previous page)

Conclusions: This is the first study which suggests that PAMs alone or co-administration with low doses of TMZ may be a potential adjuvant to reduce the toxicity of TMZ and to abrogate drug resistance for the effective treatment of glioma.

Keywords: Natural plant antimicrobial solution (PAMs), Monoamine oxidase a (MAO a), Temozolomide (TMZ), Glioblastoma, Glioma, Reduce glioma growth

\section{Background}

It has been shown that monoamine oxidase A (MAO A) is overexpressed in prostate cancer [1], glioma [2] and Hodgkin lymphoma [3], inhibiting MAO A reduces tumorigenesis and metastasis. MAO A is located in the outer membrane of mitochondria, catalyzes oxidative deamination of neurotransmitters or dietary amines and produces $\mathrm{H} 2 \mathrm{O} 2$ [4, 5]. MAO A inhibitors have been used for decades for the treatment of neuropsychiatric disorders [6].

Glioblastoma (GBM) is the most aggressive form of primary brain tumors with a median survival of 14 months from the time of diagnosis $[7,8]$. The standard treatments of newly diagnosed glioblastoma (GBM) are surgery, radiation therapy administered concurrently with oral temozolomide (TMZ), and six cycles of adjuvant TMZ therapy [9]. Unfortunately, less than $10 \%$ of the 5-year survival rate accounts for high-grade glioma patients treated with the standard radiotherapy and adjuvant chemotherapy [10]. Almost half of all gliomas are neither TMZ responsive nor susceptible to radiotherapy. Further, increasing the dose of TMZ, a DNA alkylating agent, will increase the toxicity to the bone marrow [11]. Thus, better treatment for GBM is urgently needed. Our previous study showed that MAO A inhibitor clorgyline combined with non-toxic dose TMZ reduced the tumor growth and prolong the survival in animal model [2].

Plant Antimicrobial Solution (PAMs) has anti- inflammation effect, was used for wound infection and festering, cell necrosis, dry gangrene and blood circulation obstacles [12] and was approved to be used as a hospital preparation by China Yunnan Food and Drug Administration.

PAMs is a mixture of Chinese herbal medicine consists of plants, including Carthamus tinctorius, Cymbopogon distans, Lithospermum erythrorhizon, and Solanum indicum, and Blumea balsamifera. we have identified two active compounds from PAMs including Hydroxysafflor yellow A (HSYA) in Carthamus tinctorius and Allantoin in Cymbopogon distans. HSYA exhibited anti-cancer and anti-inflammation function [12] while Allantoin has wound healing function [13]. Recently, we found Shikonia from Lithospermum erythrorhizon inhibited MAO A catalytic activity (unpublished data). Using network pharmacology from three database (TCMSP, Batman and YaTCM), we identified 158 compounds from the herb plants present in PAMs which may be the active components. This information will help us purify and identify additional active ingredients in PAMs by HPLC, GC, and Mass Spectroscopy.

Previous studies showed that PAMs inhibits the TNF$\alpha / \mathrm{IFN}-\gamma$-induced inflammatory cytokines production in $\mathrm{HaCaT}$ cells and ameliorates imiquimod- induced psoriasis-like skin inflammation in vivo through inhibiting the translocation of p65 in NF- $\mathrm{\kappa B}$ signaling pathways [12]. Our previous studies showed that treatment with MAO A inhibitor increased TNF- $\alpha$ positive cell population in tumors from glioma animal model [2]. Recently, it has been reported that treatment with MAO A inhibitor reduced the expression of the oncogene NF- $\mathrm{kB}$ in prostate cancer [14]. Taken together, this data suggests that MAO A inhibitors regulate the inflammatory response to suppress tumor progression. These findings led us to study if PAMs may have similar properties as a MAO A inhibitor.

\section{Methods}

\section{Preparation of PAMs}

PAMs was obtained from the Institute of Yunnan Folk Medicine and produced by Yunnan Puer Danzhou Pharmaceutical Co., Ltd. (Yunnan Province, P.R. China) [12]. Briefly, $5 \mathrm{ml}$ medicinal plants mixture PAMs including Carthamus tinctorius, Cymbopogon distans, Lithospermum erythrorhizon, Solanum indicum, and Blumea balsamifera, was diluted with $5 \mathrm{ml} \mathrm{H} 2 \mathrm{O}$, concentrated by vacuum at $30^{\circ} \mathrm{C}$ for $1-2 \mathrm{~h}$. Another $5 \mathrm{ml}$ PAMs and $5 \mathrm{ml} \mathrm{H} 2 \mathrm{O}$ mixture were added, vacuumed again to $2 \mathrm{ml}$. The concentrated sample was lyophilized $\left(-80^{\circ} \mathrm{C}\right)$ overnight to powder. The dried PAMs powder (40 mg) was re-dissolved in $1 \mathrm{ml} 2 \%$ ethanol kept at $20^{\circ} \mathrm{C}$ until use.

\section{Cell culture}

Human glioma cell lines U251S (TMZ sensitive) U251R (TMZ resistant), and mouse glioma cell line GL-26 with luciferase were provided by Dr. Florence Hofman at the University of Souther California; Glioma cell lines [15] were cultured in $10 \%$ fetal bovine serum in Dulbecco's 
Modified Eagle's Media (Life Technologies, Carlsbad, CA, USA) supplemented with $100 \mathrm{U} / \mathrm{ml}$ penicillin and $0.1 \mathrm{mg} / \mathrm{ml}$ streptomycin in a humidified incubator at $37^{\circ} \mathrm{C}$ and $5 \% \mathrm{CO} 2$.

\section{MAO a catalytic activity assay}

MAO A catalytic activity was determined by radioassay as described previously [1, 3]. Human prostate cancer LNCaP cells and mouse glioma GL26 cells were used. Clorgyline (Sigma-Aldrich) was pre-incubated with cells at $37^{\circ} \mathrm{C}$ for $20 \mathrm{~min}$, then the substrate $1 \mathrm{mM}{ }^{14} \mathrm{C}$-5-hydroxytryptamine (5-HT) was added, incubated for 20 $\min$ at $37^{\circ} \mathrm{C}$. At the end of the incubation, the reaction product was extracted, and the radioactivity was determined by the scintillation counter (LS 6500, Beckman coulter, Inc., CA, USA).

\section{MTS assay}

Glioma cells U251S, U251R, or GL-26 $\left(5 \times 10^{3}\right.$ cells/well) were seeded in 96-well plates and treated with PAMs at various concentrations $(0-150 \mu \mathrm{g} / \mathrm{ml})$ for $48 \mathrm{~h}$. Cell proliferation was determined by an MTS assay kit (Promega, WI, USA). Briefly, MTS reagent ( $20 \mu \mathrm{l} /$ well) was added into each well and incubated for $4 \mathrm{~h}$ in the presence of $5 \% \mathrm{CO} 2$ at $37^{\circ} \mathrm{C}$. The plate was gently agitated prior to colorimetric analysis, the reaction product of MTS was measured at $490 \mathrm{~nm}$ and quantified using a microplate reader Synergy HTX (Bio-Tek, Winooski, VT, USA). Data was plotted using GraphPad Prism (GraphPad Software, San Diego, CA, USA). For the combined treatment with TMZ (Sigma-Aldrich), $5 \times 10^{3}$ glioma cells were seeded per well in triplicate and pre-treated with TMZ $(15 \mu \mathrm{M})$ for $48 \mathrm{~h}$ followed by incubation of PAMs and TMZ for $48 \mathrm{~h}$. All experiments were repeated at least three times.

\section{Colony forming assay}

Glioma cells were seeded in 96-well plates, various concentrations of PAMs with or without TMZ $(15 \mu \mathrm{M})$ were incubated for $48 \mathrm{~h}$. After $48 \mathrm{~h}$, cells were re-seeded 500 cells/per well with fresh medium in duplicate. Cells were incubated for an additional 8 to 10 days; colonies were visualized by staining with $1 \%$ methylene blue in methanol for $4 \mathrm{~h}$ and quantified. Colonies were enumerated from pictures of plates using software tools (open CFU).

\section{Cell migration assay}

Glioma cells $\left(1.2 \times 10^{6}\right.$ cells/ well $)$ were seeded in 24 well plates for $24 \mathrm{~h}$, then the monolayer was scratched with a new $200 \mu \mathrm{l}$ pipette tip, fresh medium containing various concentrations of PAMs with our without $15 \mu \mathrm{M}$ TMZ, were incubated for $24 \mathrm{~h}$. Migrated cell numbers in the scratched region were visualized by staining with $1 \%$ methylene blue in methanol for $4 \mathrm{~h}$ and quantify by imaging. (Image J software, National Institute of Health, Bethesda, MD, USA.

\section{Animal models}

Male 4- to 6-weeks-old C57BL/6 mice were purchased from Harlan (Indianapolis, IN), house in the animal research facility at University of Southern California (USC), fed with a normal diet. All animal protocols were approved by the Institutional Animal Care and Use Committee (IACUC No. 20212) of USC. Mice were sacrificed by carbon dioxide (CO2). For subcutaneous model, Xenograft tumors were established via subcutaneous inoculation of $5 \times 10^{3}$ luciferase-positive mouse glioma GL-26 cells into the flank of the mice. Six days after the inoculation, mice were subcutaneously injected with clorgyline $(10 \mathrm{mg} / \mathrm{kg})$, PAMs $(48 \mathrm{mg} / \mathrm{kg})$ and vehicle respectively for 14 days. Subcutaneous injections were administered in the space between the skin and the underlying muscles over the shoulders.

For intracranial model: mice were treated with (1) PAMs (2) TMZ (1 mg/kg) alone, (3) TMZ and PAMs combination for 14 days. PAMs was injected daily intranasally (IN). TMZ was dissolved in water and administered by gavage for 10 days. Combination of TMZ and PAMs were given with the same schedule as each agent alone.

\section{Statistical analysis}

All data was presented as the mean \pm standard error (SE) values and analyzed using GraphPad Prism 6 (GraphPad Software, San Diego, CA, USA). T-test was performed for comparison with multiple groups. In brief, we analyzed the data using Prism (two samples and paired) by t-test analysis. A $p$-value of $p<0.05$ was considered statistically significant.

\section{Results}

PAMs inhibits MAO a catalytic activity in glioma cells The effect of PAMs on the inhibition of MAO A catalytic activity was determined in mouse glioma GL-26 cells [2] and human prostate LNCaP cells which have been reported to express high MAO A activity [1]. Our results showed that IC50 of PAMs is $80.0 \mu \mathrm{g} / \mathrm{ml}$ in GL26 cells and $112.1 \mu \mathrm{g} / \mathrm{ml}$ in LNCaP cells (Fig. 1a). These results indicate that PAMs inhibits MAO A catalytic activity in both glioma and prostate cancer cell lines with almost similar potency.

PAMs inhibits the growth of human TMZ-sensitive U251S, TMZ-resistant U251R cells and mouse glioma GL-26 cells

To determine the effects of PAMs on the cell viability on glioma. Human glioma cell lines U251S, U251R, and mouse glioma GL-26 cells were used. In this study, we treated the cell with PAMs at $24 \mathrm{~h}$ and $48 \mathrm{~h}$, with 
(a)
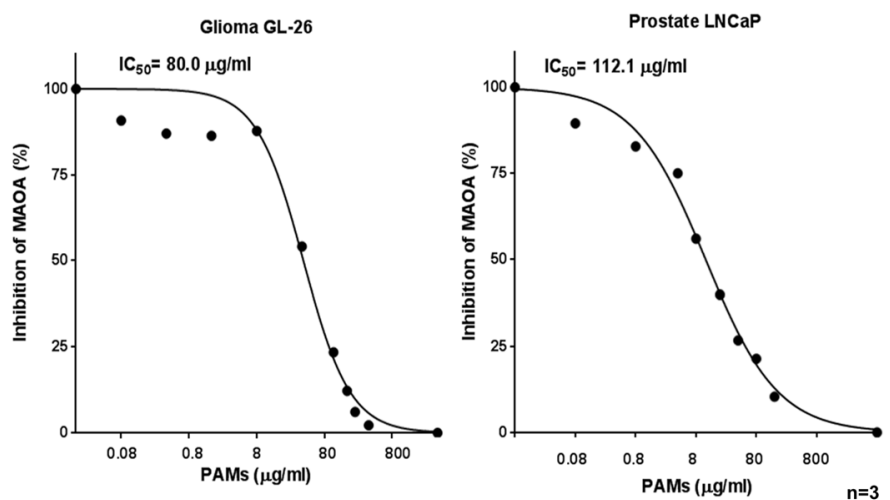

(b)
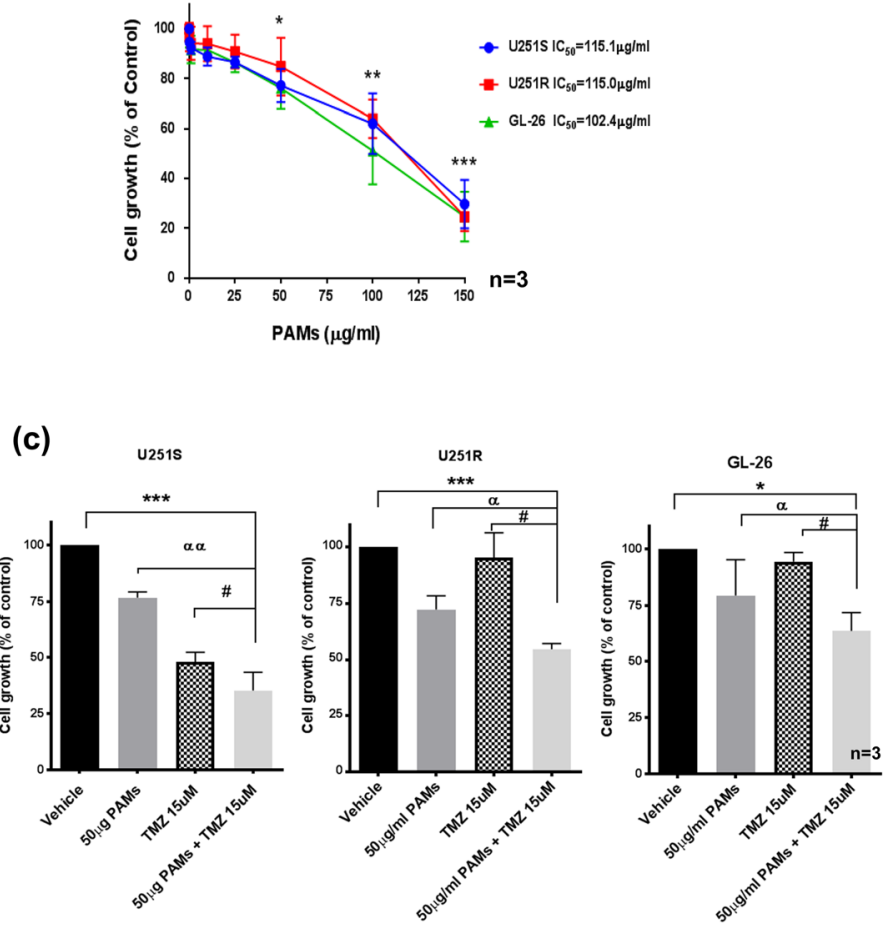

(d)

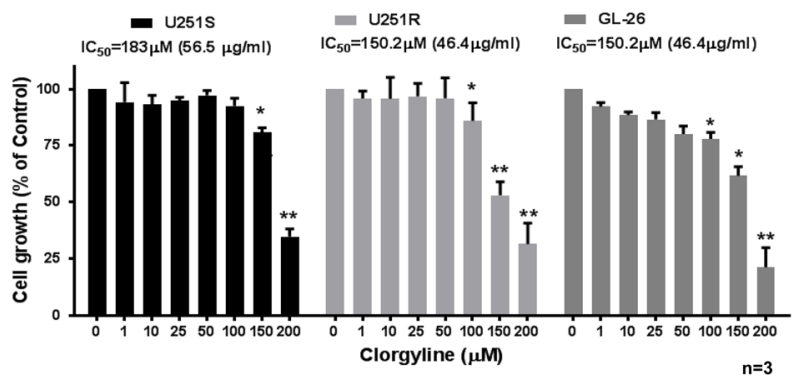

Fig. 1 (See legend on next page.) 
(See figure on previous page.)

Fig. 1 PAMs reduced MAO A activity and cell growth in glioma cells in vitro. a PAMs inhibited MAO A catalytic activity. The effect of PAMs on MAO A catalytic activity was determined in mouse glioma GL-26 and human prostate LNCaP cells. PAMs at appropriate concentrations were preincubated at $37^{\circ} \mathrm{C}$ for $20 \mathrm{~min}$, then the substrate serotonin (5HT) was added for MAO A catalytic activity assay, see text for detail. 100\% of MAO A catalytic activity was 36.65 or $29.86 \mathrm{nmol} / 20 \mathrm{~min} / \mathrm{mg}$ in prostate cancer or glioma respectively. $\mathbf{b}$ Effect of PAMs. on cell growth in human glioma TMZ-sensitive (U251S), TMZ-resistant (U251R) and mouse GL- 26 cells as determined by MTS assay. $5 \times 10^{3}$ cells were seeded in each well, incubated with PAMs at $(0-150 \mathrm{\mu g} / \mathrm{ml})$ for $48 \mathrm{~h}$, MTS assay was then performed. c PAMs in combination with low dose TMZ reduced cell growth in U251S, U251R, and GL-26 cells. Cells were treated with PAMs $(50 \mu \mathrm{g} / \mathrm{ml})$, TMZ $(15 \mu \mathrm{M})$, PAMs $(50 \mu \mathrm{g} / \mathrm{ml})+$ TMZ $(15 \mu \mathrm{M})$ for $48 \mathrm{~h}$, MTS assay was then performance. Data represent the mean \pm SEM. The $p$ value was calculated by t-test. ${ }^{*} p<0.05,{ }^{* *} p<0.01,{ }^{* * *} p<0.001$ compared to control $(0 \mu \mathrm{g}) . \# p<0.05$, PAMs $(50 \mu \mathrm{g} / \mathrm{ml})+\mathrm{TMZ}(15 \mu \mathrm{M})$ compared to TMZ alone. $\mathbf{d}$ Effect of MAO A inhibitor clorgyline on cell growth. Cells (U251S, U251R, and GL-26) were seeded and incubated with clorgyline (0-200 $\mu \mathrm{M})$. The IC50 of clorgyline is 56.5, 46.4, and 46.4 $\mu \mathrm{g} / \mathrm{ml}$ for U251S, U251R, and GL-26 cells. Experiments were performed in triplicate and repeated three times with similar results $(n=3)$

different concentrations. We found $48 \mathrm{~h}$ was the optimum condition; thus, we showed the data at $48 \mathrm{~h}$. Cells were incubated with various concentrations of PAMs $(0.1$ to $150 \mu \mathrm{g} / \mathrm{ml})$ for $48 \mathrm{~h}$. Cell viability was determined by MTS assay. PAMs showed dose-dependent inhibition with 50\% inhibitory concentrations (IC50) of $115.1,115.0$, and $102.4 \mu \mathrm{g} / \mathrm{ml}$ for U251S, U251R, and GL26 cells, respectively (Fig. 1b).

Further, the effect of PAMs in combination with low dose $15 \mu \mathrm{M}$ TMZ on inhibiting the growth of glioma cell lines (U251S, U251R, GL-26) was investigated. PAMs $(50 \mu \mathrm{g} / \mathrm{ml})$ alone inhibited the growth by 24,28 , and $21 \%$ in U251S, U251R, and GL26 cells, respectively. Combining low dose TMZ with PAMs reduced cell growth by $65 \%, 46$ and $36 \%$ in U251S, U251R, and GL26 cells, respectively, they were more effective compared to PAMs alone $(\alpha \alpha, p<0.01$, U251S $\alpha, p<0.05, \mathrm{GL}-26)$, TMZ alone (\#, p < 0.05,U251R) or vehicle (***, $p<0.001$, U251S and U251R; *, p < 0.05, GL-26) (Fig. 1c).

We also evaluated the effect of clorgyline on human TMZ-sensitive U251S or TMZ-resistant U251R cells, and mouse glioma GL-26 cells for comparison. Clorgyline suppressed the growth of all three cell lines similarly, IC50 $=56.5$, and $46.4 \mu \mathrm{g} / \mathrm{ml}$ for U251S and R cells, $46.4 \mu \mathrm{g} / \mathrm{ml}$ for GL26 cells (Fig. 1d).

Figure 2a shows the inhibitory effect of PAMs on the growth of U251S, U251R, and GL-26 cells using colony formation assay. The quantitative data showed that PAMs suppresses cell growth and colony formation in a dose-dependent manner (Fig. 2a). $50 \mu \mathrm{g} / \mathrm{ml}$ of PAMs reduced the growth by 24,17 , and $17 \%$ in U251S, U251R, and GL-26 glioma cells respectively (Fig. 2a). PAMs showed its effect in a dose dependent manner. With colony reduction efficacy of $34,45,33 \%$ in U251S, U251R, and GL-26 at $100 \mu \mathrm{g} / \mathrm{ml}$, and 74, 80, 46\% in U251S, $\mathrm{U} 251 \mathrm{R}$, and GL-26 at $150 \mu \mathrm{g} / \mathrm{ml}$ (Fig. 2a).

PAMs $(50 \mu \mathrm{g} / \mathrm{ml})$ in combination with low dose TMZ $(15 \mathrm{uM}, 2.91 \mu \mathrm{g} / \mathrm{ml})$ suppressed colony formation by 70 , $35,30 \%$ in U251S, U251R, and GL-26 cells, respectively (**, $p<0.01$ in U251S; *, $p<0.05$ in U251R and GL-26) (Fig. 2b,). 15uM TMZ inhibited colony formation by 55 , $15,13 \%$ in U251S, U251R, and GL-26 cells. This data indicates that PAMs in combination with TMZ reduces cell growth in vitro more effectively than each compound alone.

\section{PAMs inhibits the migration of human TMZ-sensitive} U251S, TMZ-resistant U251R or mouse glioma GL-26 cells The inhibitory effect of PAMs on the migration of glioma cells was studied in all three cell lines. Glioma cells were treated with various concentrations $(0,50,100$, or $150 \mu \mathrm{g} / \mathrm{ml}$ ) of PAMs for $24 \mathrm{~h}$. As shown in Fig. 3a, $50 \mu \mathrm{g}$ of PAMs significantly inhibited migration by $25 \%\left({ }^{*}, p<\right.$ $0.05), 32 \%(*, \mathrm{p}<0.05), 27 \%(*, \mathrm{p}<0.05)$ in U251S, U251R, and GL-26 cells, respectively (Fig. 3a). Further increase of PAMs concentrations show that PAMs suppresses the migration of glioma cells in a dosedependent manner. Higher dose of PAMs (100 or $150 \mu \mathrm{g} / \mathrm{ml}$ ) was more effective, with inhibition of $56 \%$ $\left.{ }^{* * *}, p<0.001\right), 67 \%(* *, \mathrm{p}<0.001), 67 \%(* *, \mathrm{p}<0.001)$ in U251S, U251R, and GL-26 at $100 \mu \mathrm{g} / \mathrm{ml} ; 77 \%$ (**\%, p < $0.001), 80 \% \quad(* * *, p<0.001), 87 \%$ (***, $\mathrm{p}<0.001)$ in U251S, U251R, and GL-26, at $150 \mu \mathrm{g} / \mathrm{ml}$. Thus, PAMs significantly reduced cell migration in all glioma cell lines we studied (Fig. 2a).

Next, the effect of combining PAMs with low dose TMZ was assessed. Figure $3 \mathrm{~b}$ shows that $50 \mu \mathrm{g}$ PAMs in combination with $15 \mu \mathrm{M}$ TMZ significantly inhibited migration compared to vehicle by $52 \%$ (***;, $\mathrm{p}<0.001$ ), $29 \%$ $(* *, p<0.01), 55 \%(* * *, \mathrm{p}<0.001)$ in U251S, U251R, and GL-26 cells, respectively. 15uM TMZ alone inhibited cell migration by $40,8,9 \%$ in U251S, U251R, and GL-26 cells. When compared with TMZ alone, PAMs in combination with TMZ inhibited more effectively: by $12 \%$ (\#, $p<0.05), 21 \%$ (\#\#, $\mathrm{p}<0.01$ ), 46\% (\#\#, $\mathrm{p}<0.001)$ in U251S, U251R, and GL-26 cells (Fig. 3b), respectively. This finding suggests PAMs in combination with TMZ show more than additive effect compared with each compound alone in the migration assay (Fig. 3b).

PAMs reduces the growth of tumors derived from GL-26 glioma cells implanted subcutaneously in C57BL/6 mice To ascertain the in vivo effect of PAMs on tumor growth, murine glioma GL-26 cells were subcutaneously 
(a)
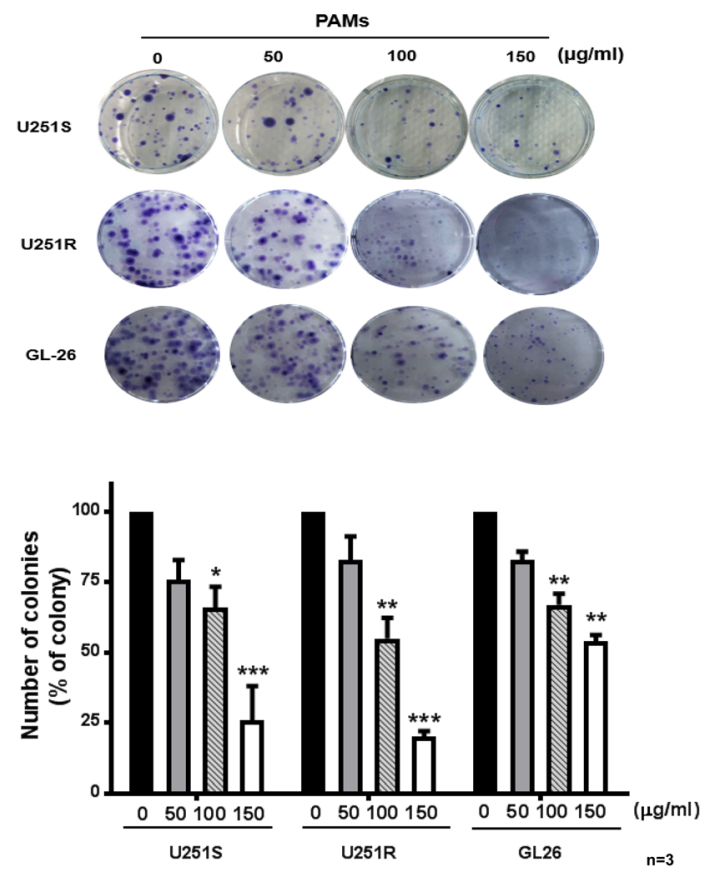

(b)
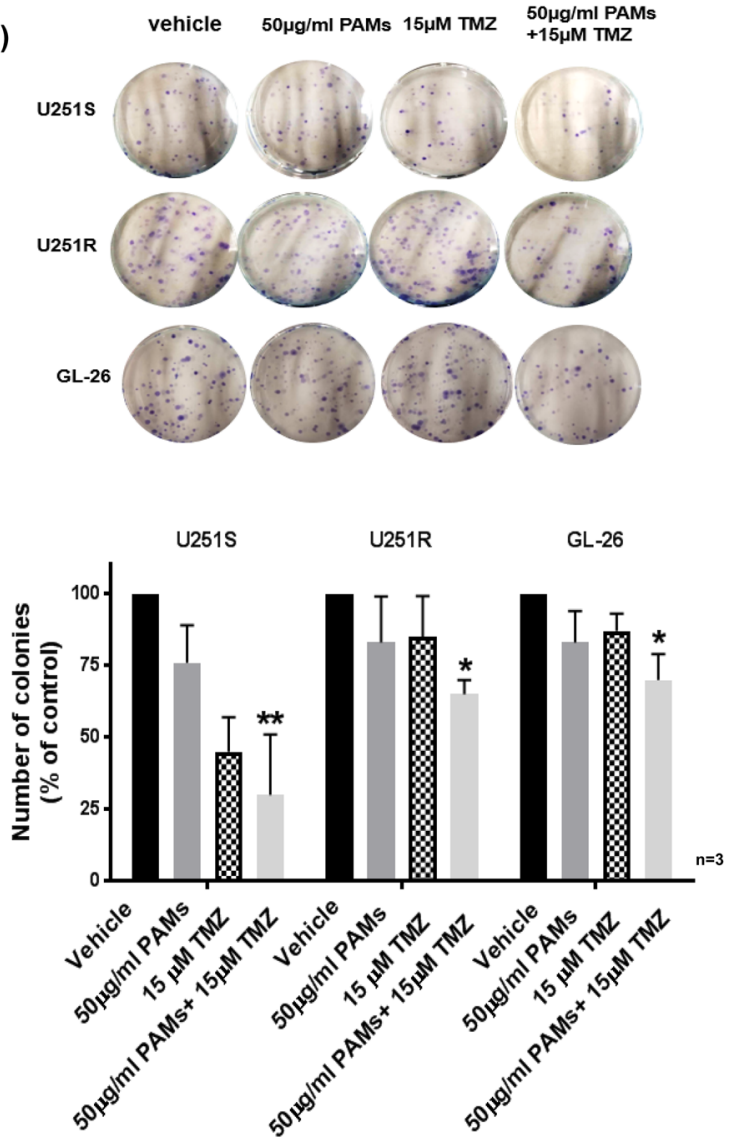

Fig. 2 PAMs reduced cancer cell growth in human glioma TMZsensitive (U251S), TMZ-resistant (U251R) and mouse GL-26 cells as determined by colony formation assay. a PAMs reduced cell growth as determined by colony formation in glioma cell lines (U251S, U251R and GL-26). 500 cells were seeded in each well, treated with PAMs for $48 \mathrm{~h}$, incubated for additional 8-10 days, cells were fed every two days. b Cells were treated by PAMs $(50 \mu \mathrm{g} / \mathrm{ml})$, TMZ $(15 \mu \mathrm{M})$, or PAMs $(50 \mu \mathrm{g} / \mathrm{ml})+$ TMZ $(15 \mu \mathrm{M})$. Combination of PAMs with low dose TMZ significantly inhibited cell growth as shown by colony formation assay. Data represent the mean \pm SEM. The $p$-value was calculated by t-test. ${ }^{*} p<0.05,{ }^{* *} p<0.01$, compared to untreated control $(0 \mu \mathrm{g} / \mathrm{ml})$. The untreated control group was taken as $100 \%$. After combined treatment of PAMs and TMZ, percentage of colonies were 30, 60, and 60 (colony size> $100 \mathrm{~mm}$ ) in U251S, U251R, and GL26 cells respectively. Experiments were performed in triplicate and repeated three times with similar results $(n=3)$

implanted in C57BL/6 mice. Six days post implantation (i.e. day 0 for drug treatment), mice were imaged and treated with PAMs $(48 \mathrm{mg} / \mathrm{kg})$, clorgyline $(10 \mathrm{mg} / \mathrm{kg})$ or vehicle. All treatments were administered subcutaneously daily for 14 days. Tumor size was measured by imaging and the imaging data shows decreased tumor size after treating with PAMs or clorgyline (Fig. 4a and b) and by the ellipsoid volume formula $(\pi / 6 \times \mathrm{L} \times \mathrm{W} \times \mathrm{H}$ and $1 / 2 \times \mathrm{L} \times \mathrm{W} \times \mathrm{H}$ ) (Fig. $4 \mathrm{c}$ and d). PAMs reduced tumor size as determined by both methods on day 13 (47\%) (Fig. 4d). As shown in Fig. 4d, both PAMs and clorgyline reduced tumor growth significantly and similarly (day $13, *, p<0.05$ PAMs group compared to vehicle, \#, $p<0.05$ clorgyline compared to vehicle). These data indicate that PAMs reduces tumor growth in a glioma mouse model. Similar results were obtained in mice treated with PAMs or clorgyline, i.e. tumor growth reduced by 53\% (Fig. 4d). PAMs or clorgyline inhibited MAO A catalytic activity by $25 \%(*, p<0.05$, Fig. 4 e) and $90 \%(* *, p<0.001$, Fig. 4e) respectively. No change in body weight occurred when mice were treated with PAMs, clorgyline or vehicle (Fig. 4f). This study shows that PAMs inhibits MAO A activity and glioma cell growth without toxicity.

The effect of PAMs on the growth of tumors derived from GL-26 glioma cells intracranially implanted in C57BL/6 mice

Mice were intracranially implanted with GL-26 glioma cells having luciferase activity. Six days later, mice were treated with PAMs $(48 \mathrm{mg} / \mathrm{kg})$ daily intranasally for 14 days. PAMs reduced the brain tumor size (Fig. 5a) and tumor weight compared to vehicle $\left({ }^{*} p<0.05\right.$, Fig. 5b). MAO A activity was significantly reduced in PAMs treated brain tumor (25\%) compared to the vehicle treated (*, p $<0.05$, Fig. 5c).

PAMs significantly increased survival (19 days) compared to vehicle (16 days) (Fig. $5 \mathrm{~d}$ ). The current standard chemotherapeutic for glioma is TMZ, whose efficacy is 
(a)

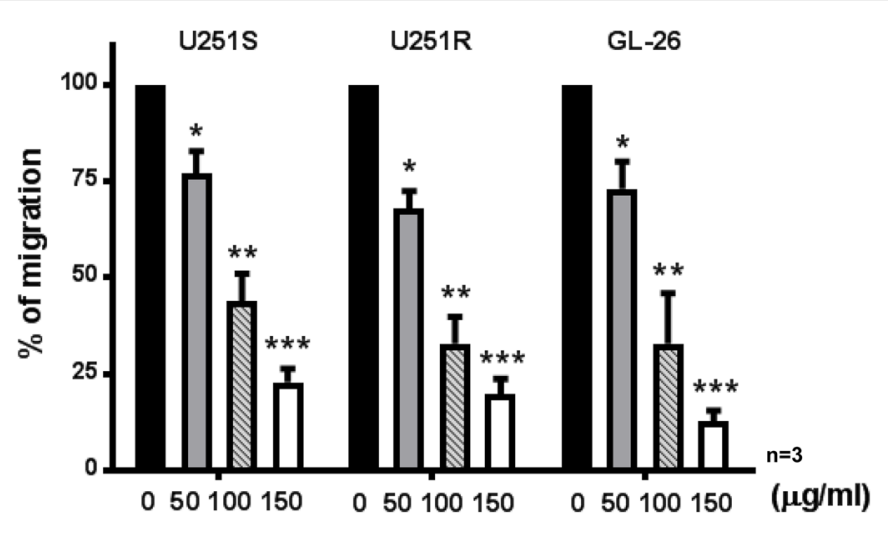

(b)

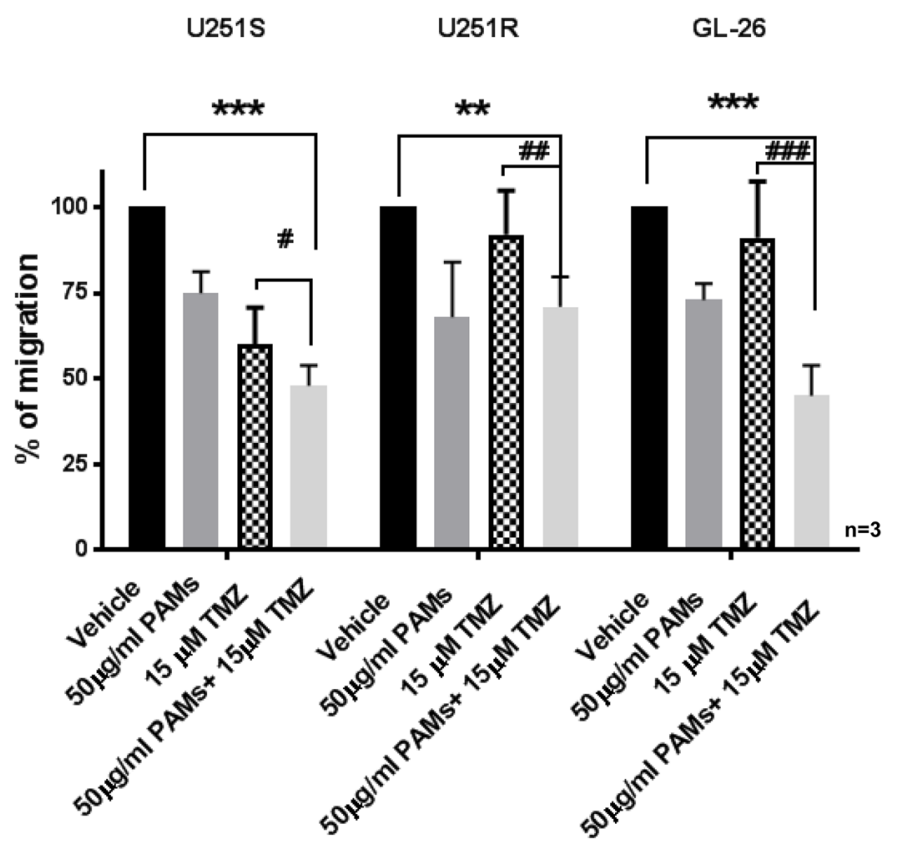

Fig. 3 PAMs suppressed the cells migration in human glioma TMZ-sensitive (U251S), TMZ- resistant (U251R) and mouse GL-26 cells cancer either alone or in combination with TMZ We determine the migration of glioma cells by treating with (a) PAMs alone, $1.2 \times 10^{6}$ cells were seed in 24 well and incubated PAMs at various concentrations $(0,50,100,150 \mathrm{\mu g} / \mathrm{ml})$ for $24 \mathrm{~h}$ or (a) PAMs in combination with low dose of TMZ. Cells were treated by PAMs $(50 \mu \mathrm{g} / \mathrm{ml})$, TMZ $(15 \mu \mathrm{M})$, or PAMs $(50 \mu \mathrm{g} / \mathrm{ml})+\mathrm{TMZ}(15 \mu \mathrm{M})$ and then cell numbers were counted and quantified. Data represent the mean \pm SEM. The $p$-value was calculated by t-test. ${ }^{*} p<0.05,{ }^{* *} p<0.01,{ }^{* * *} p<0.001$ compared to untreated control. \#p $<0.05$, \#\#p $<0.01$, $\# \# \# p<0.001$ compared to TMZ alone). The untreated control groups were taken as 100\%. Experiments were performed in triplicate and repeated three times with similar results $(n=3)$

accompanied by toxicity and the onset of resistance. This result suggests that PAMs may be used to treat glioma without toxicity. Prolonged treatment with TMZ did not significantly affect tumor growth based on the tumor size (Fig. 6a) and tumor weight (Fig. 6b).

Taken together, PAMs or PAMs in combination with TMZ significantly reduced tumor size and weight (* $\mathrm{p}<$ 0.05, Fig. 6a and b). Although, combined treatment had the same effect as PAMs alone; but the survival was increased significantly than TMZ or PAMs alone (Fig. 6c). MAO A activity was also inhibited by PAMs alone or in combination with TMZ (Fig. 6d). PAMs decreased tumor growth and prolonged the survival of mice bearing invasive glioma brain tumors. This finding suggests that PAMs reduces tumor growth and increases survival in vivo. In these experiments, we used non-toxic low dose TMZ (1 mg/kg), which by itself has no significant effect on tumor size (Fig. 6a) or weight (Fig. 6b).

\section{Discussion}

Increased MAO A has been reported in several types of solid tumors including prostate cancer $[1,16]$, glioma 
(a)

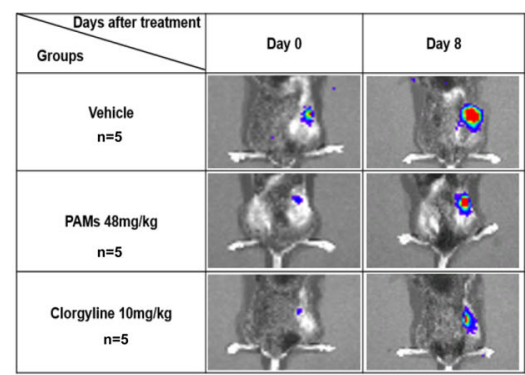

(b)

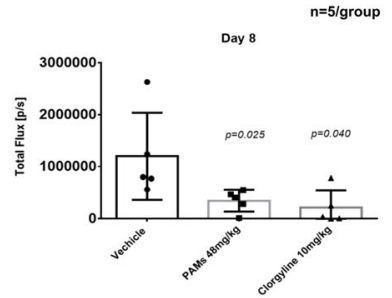

(c)

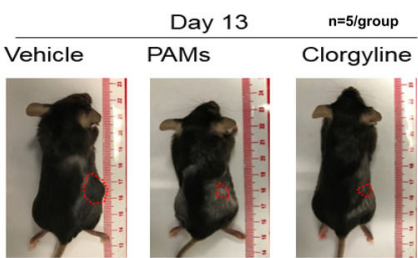

(d)

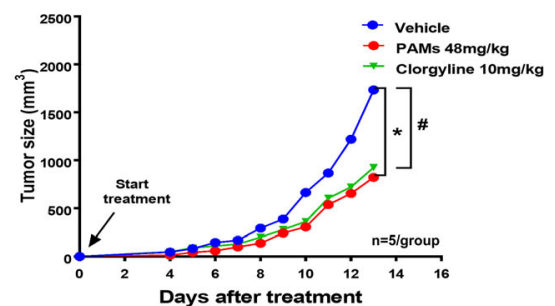

(e)

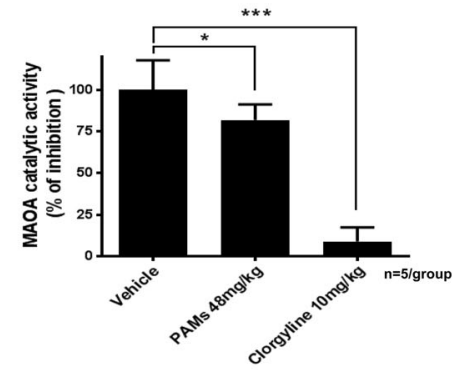

(f)

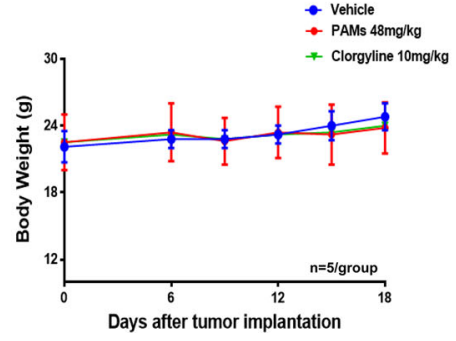

Fig. 4 PAMs reduced tumor growth, similar to MAO A inhibitor clorgyline in subcutaneous mouse glioma C57BL/6 mouse model. Mice were implanted subcutaneously with $5 \times 10^{3}$ luciferase-positive mouse glioma GL-26 cells, then were treated with MAO A inhibitor clorgyline (10 mg/kg), PAMs ( $48 \mathrm{mg} / \mathrm{kg})$, and vehicle for 14 days. a Tumor sizes were reduced by PAMs and clorgyline at day 8 after the implantation of GL-26 cells in C57BL/6 mice as shown by images. Representative images of tumor size reduced by PAMs or clorgyline on day 0 and 8 after treatment were shown. b Qualitative representation of bioluminescence imaging conducted at day 8. c PAMs and clorgyline reduced tumor size at day 13 in subcutaneously implanted GL-26 cells in C57BL/6 mice. d PAMs and clorgyline reduced tumor size compared to vehicle. e MAO A catalytic activity was reduced by PAMs and clorgyline. f No change in body weight was observed for all three groups, i.e. PAMs, clorgyline, and vehicle. Each group $n=5$. Data represent the mean \pm SEM. The $p$-value was calculated by t-test. ${ }^{*} p<0.05$, PAMs group compared to vehicle, $\# p<0.05$ clorgyline compared to vehicle

[2], renal carcinoma [14] and lymphoma [3]. MAO A inhibitors have been shown to reduce glioma in both cell and animal models [2]. MAO A inhibitors and its conjugate reduced the prostate cancer progression and metastasis [1], and suppressed cell growth in glioma [2] and Hodgkin lymphoma [3]. These work underscore the significance of targeting MAO A for cancer therapy.

The natural plant antimicrobial solution PAMs, which contains multi-bioactive components extracted from Chinese natural and folk medicinal plants has been used clinically in China for hundreds of years. Its effective formula has been shown to prevent inflammation via NF$\kappa B$ signaling pathways. Recent work showed that PAMs inhibits TNF- $\alpha / \mathrm{IFN}-\gamma$-induced inflammatory cytokines production and inhibits the translocation of p65 in NF$\kappa B$ signaling pathways $[12,17,18]$.

The tumor microenvironment of glioma is largely comprised of inflammatory molecules that affect neoplastic process, proliferation, survival and migration of tumors through inflammation and oxidative stress pathways [19]. It has been suggested that NF- $\mathrm{kB}$ activation in cancers may be the result of either exposure to proinflammatory stimuli in the tumor microenvironment or mutational activation of upstream components in IкK$\mathrm{NF}-\kappa \mathrm{B}$ signaling pathways [17]. It provided evidence that $\mathrm{NF}-\mathrm{kB}$ is a key transcription factor for the proliferation and survival of glioma cells [20,21].

This study shows the potential use of PAMs for the treatment of glioblastoma via MAO inhibition.

Multiple functions of PAMS have been reported. We have shown previously the antimicrobial effects of PAMs, on Pseudomonas aeruginosa, Staphylococcus aureus, Escherichia. coli, Canidia Albicans, and Aspergillus niger [22]. PAMs remarkably inhibits the growth of Staphylococcus aureus and enhance the wound-healing by increasing the permeability of bacterial cell 
(a)
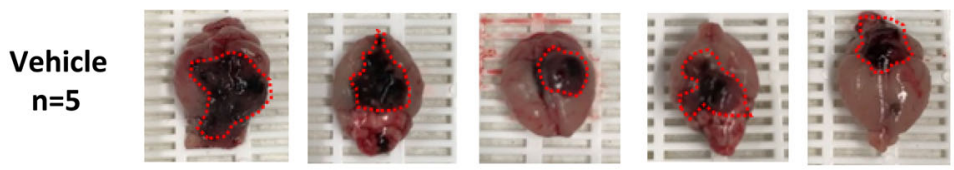

PAMs

$n=4$

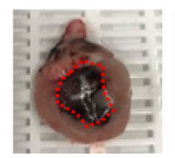

(b)

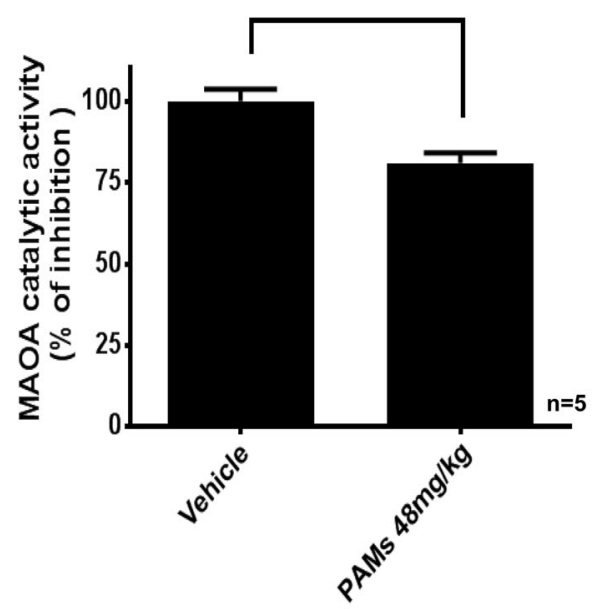

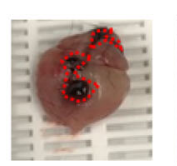

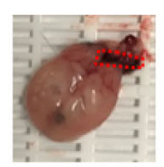

(c)

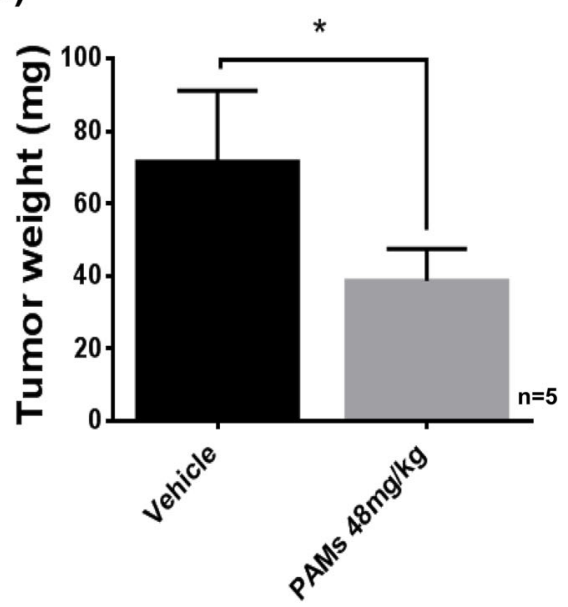

(d)

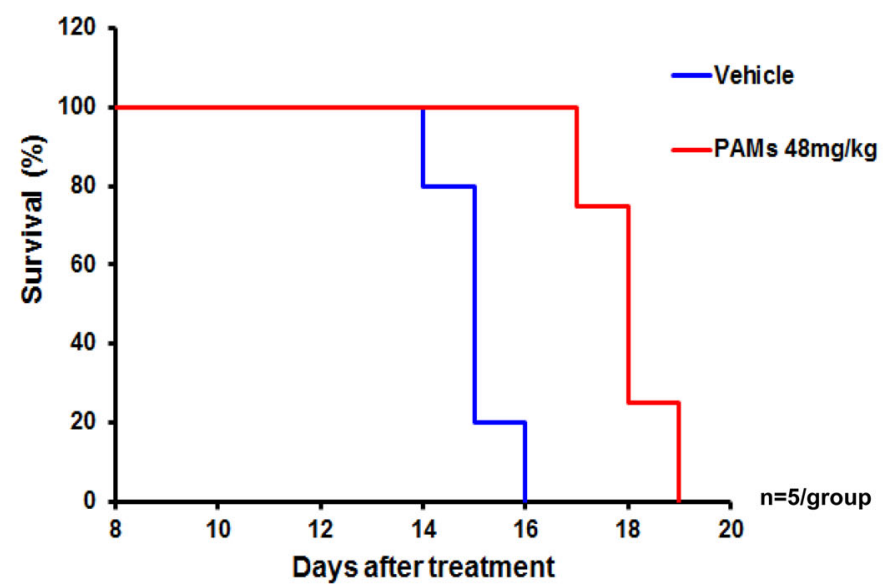

Fig. 5 PAMs reduced tumor growth and increased survival in intracranial mouse GL-26 glioma C57BL/6 mouse model. Mice were implanted intracranial with mouse glioma GL-26 cells and treated with PAMs $(48 \mathrm{mg} / \mathrm{kg})$ or vehicle for 14 days. PAMs treated mice (a) reduced tumor size, $\mathbf{b}$ reduced tumor weight, and $\mathbf{c}$ inhibited MAO A catalytic activity in tumor compared to vehicle control. PAMs treated mice also had (d) increased survival compared to vehicle control. Each group $n=5$

membranes, leakage of contents, and eventually the death of Staphylococcus aureus.

PAMs reduced liver cancer growth by regulating apoptosis in HepG2 cells [23]. Also, we showed the anticancer effect of PAMs in leukemia cells was mediated by anti-proliferation [24]. Recently, we eported that PAMs could also inhibit the tumor growth of cancers by downregulating the expressions of inflammation and vascular growth associated with TNF- $\alpha$ and VEGF [12].

Our studies showed that treatment with MAO A inhibitor increased TNF- $\alpha$ positive population in tumors from animal models [2]. Recently, it has been reported that treatment with MAO A inhibitor reduced the expression of the oncogene NF- $\mathrm{KB}$ in prostate cancer [25-28]. These findings 


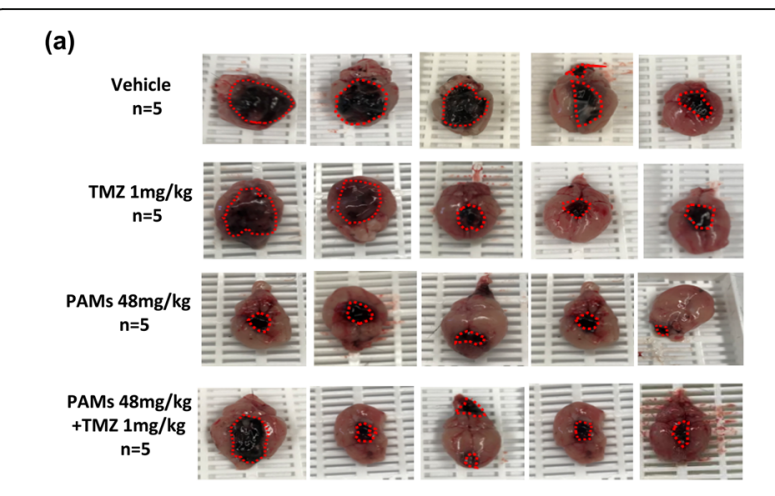

(b)

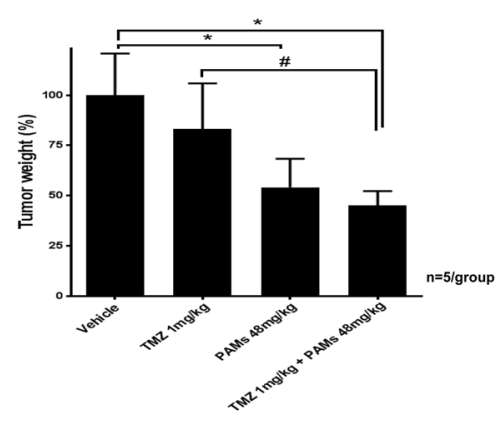

(c)

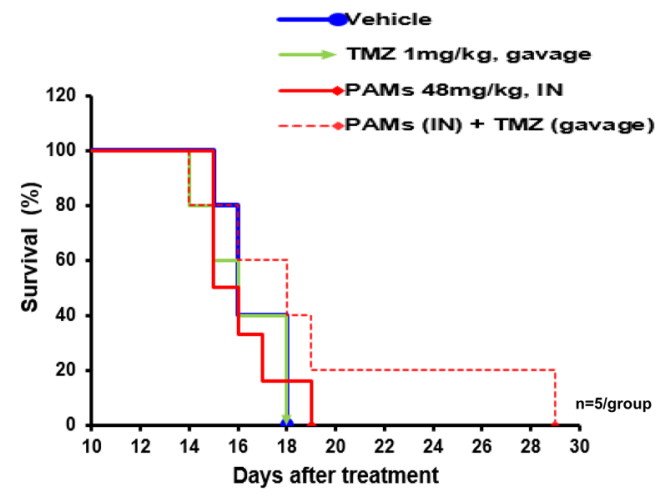

(d)

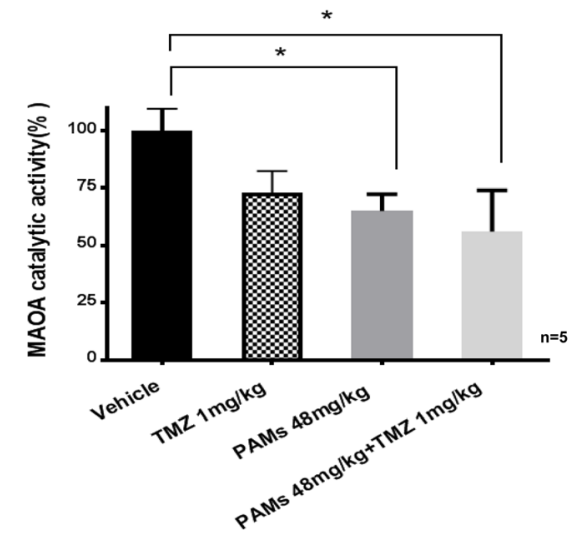

Fig. 6 PAMs alone or in combination with TMZ increased survival in intracranial glioma C57BL/6 mouse model. Mice were implanted intracranially with mouse glioma GL-26 cells and treated with vehicle, and PAMs (48 mg/kg) by daily intranasal (IN) for 14 days, or TMZ $(1 \mathrm{mg} / \mathrm{kg})$ alone by oral gavage for 10 days, and in combination with PAMs and TMZ. a PAMs alone or in combination with TMZ reduced tumor growth in intracranial glioma mouse model. Mice with glioma intracranial tumor xenografts were treated by PAMs (48 $\mathrm{mg} / \mathrm{kg}$ ), TMZ (1 mg/kg), PAMs (48 mg/kg) + TMZ (1 mg/kg), and vehicle. Each group $\mathrm{n}=5$. $\mathbf{b}$ PAMs and PAMs $(48 \mathrm{mg} / \mathrm{kg})+$ TMZ (1 $\mathrm{mg} / \mathrm{kg}$ ) significantly reduced the tumor weight. c PAMs and PAMs (48 mg/kg) + TMZ (1 mg/kg) increased survival compared to vehicle or TMZ group. d PAMs or PAMs (48 mg/kg) + TMZ (1 mg/kg) suppressed MAO A catalytic activity compared to vehicle. Data represent the mean \pm SEM. The $p$-value was calculated by t-test. ${ }^{*} p<0.05$, PAMs group compared to vehicle

suggest that MAO A inhibitors regulate the inflammatory response to suppress tumor progression [2], and led us to investigate if PAMs may affect MAO A activity.

Here, we demonstrate for the first time that PAMs inhibits MAO A catalytic activity. Further, PAMs reduced the growth of human glioma TMZ-sensitive U251S, TMZ-resistant U251R and mouse glioma GL-26 cells based on MTS, colony formation, and cell migration assays.

Our data shows the IC50 values of PAMs for the growth of U251S, U251R, and GL-26 cells are 115.1, 115.0, $102.4 \mu \mathrm{g} / \mathrm{ml}$ respectively, were 2 -fold better than that of clorgyline in all three cell lines. This suggests that herbal medicine mixture PAMs may have more active compounds. The effects of PAMs on normal glia cells are currently under investigation .

TMZ is the current standard therapy for Glioma patients. At least $50 \%$ of TMZ treated patients resistant to TMZ. The animal experiments were performed using subcutaneously implanted GL-26 glioma cells in mice. Treatment with PAMs significantly inhibited tumor size, similar to the MAO A specific inhibitor clorgyline. PAMs was also used to treat C57BL/6 mice after they were intracranially implanted with GL-26 glioma cells. The result showed that PAMs significantly inhibits GL- 26 tumor growth in their size and weight $(\sim 57 \%)$. Compared with the vehicle group, PAMs reduced tumor MAO A activity by $25 \%$ and improved survival tsignificantly.

We also demonstrated that combining PAMs with low dose of current standard treatment of TMZ was more effective. For the in vivo study, low dose TMZ $(1 \mathrm{mg} / \mathrm{kg})$ was used which was lower than the dose administered to patients, non-toxic [2], and no effect on the treatment of glioma. Combining PAMs with low dose TMZ decreased tumor MAO A activity to a greater extent than PAMs or TMZ alone. More importantly, the combination treatment increased survival significantly than either agent alone. TMZ alone had no effect on survival. Thus, PAMs enhances the efficacy of non-toxic low doses of TMZ. This 
is consistent with our previous finding that MAO A inhibitor clorgyline or the near-infrared-dye conjugated clorgyline (NMI) in combination with TMZ inhibits tumor growth more effectively than each agent alone [2].

Taken together, our findings suggest that PAMs inhibits MAO A activity, has greater effect in combination with non-toxic dose TMZ against glioma, and improves survival in vivo. This finding is consistent with our previous studies showing that knock-down (KD) or pharmacological inhibition of MAO A in prostate cancer and glioma reduces cancer progression $[1,2]$. Hence, the results show PAMs inhibits MAO A activity and may be used for glioma treatment.

\section{Conclusions}

This is the first study showing that the natural plant antimicrobial solution PAMs has MAO A inhibitory effect and suppresses glioma progression. PAMs has been used to treat skin inflammatory diseases and has effect on pain-releasing and wound healing. Here, we show the potential use of PAMs in combination ttherapy with non-toxic dose of TMZ for drug-sensitive and drugresistant gliomas.

\section{Abbreviations}

MAO A: Monoamine oxidase A; GBM: Glioblastoma; TMZ: Temozolomide; PAMs: Natural plant antimicrobial solution; IN: Intranasal; IACUC: Institutional Animal Care and Use Committee; IC50: 50\% inhibitory concentration

\section{Acknowledgements}

We thank Dr. Phang Cheng Tai (Departments of Biology, Georgia State University) for valuable discussion. We thank Bin Qian and Jinghua Cai, Department of Pharmacology and Pharmaceutical Sciences, School of Pharmacy, University of Southern California, Los Angeles, CA for technical assistance.

\section{Authors' contributions}

Conceived the idea of this paper JCS, Conceived and Designed the experiments: JCS, SYC and PCL. PAMs concentrate was provided from DX, CM. Performed the experiments: SYC, and PCL. Analyzed the data: PCL, and SYC. Wrote, reviewed and edited the paper: JCS, CHW and PCL. All authors have read and approved the manuscript.

\section{Funding}

This work was supported by the Tsai family Fund and Boyd-Elsie Welin Professorship to Dr. Jean Shih who is the principal investigator in these grant. Taipei Medical University, Taiwan (03G0000004A) provided Shih-Yin Chen's stipend.

\section{Availability of data and materials}

All data generated or analyzed during this study are included in this published article.

\section{Ethics approval and consent to participate}

The experimental protocol was established, according to the ethical guidelines and was approved by the Institutional Animal Care and Use Committee (IACUC) of University of Southern California (IACUC protocol number 20212). The detail of mice euthanasia methods is following the IACCU guideline, anesthesia with CO2 or isoflurane (1-3\% inhalant to effect) will be used for euthanasia of mice. Isoflurane is the standard inhalant anesthetic, delivered to effect in concentrations of 1-3\% in oxygen (up to $5 \%$ for initial induction), using a precision vaporizer. After surgery, the anesthetic monitoring of mice includes testing of rear foot reflexes before any incision is made, and continual observation of respiratory pattern, mucous membrane color, and responsiveness to manipulations and rear foot reflexes throughout the procedure. This research is not an application for clinical research, an institutional review board (IRB) is not applicable.

\section{Consent for publication}

The authors declare no conflict of interest.

\section{Competing interests}

The authors declare that they have no competing interests.

\section{Author details}

'Department of Pharmacology and Pharmaceutical Sciences, School of Pharmacy, University of Southern California, Rm. 518, 1985 Zonal Ave, Los Angeles, CA 90089, USA. 'USC-Taiwan Center for Translational Research, School of Pharmacy, University of Southern California, Los Angeles, CA 90089, USA. ${ }^{3}$ School of Pharmacy, Taipei Medical University, Taipei 110, Taiwan. ${ }^{4}$ Institute of Yunnan Folk Medicine, Kunming 650202, China. ${ }^{5}$ School of Life Sciences and Engineering, Southwest Jiaotong University, Chengdu 610031, China. ${ }^{6}$ Department of Cell and Neurobiology, Keck School of Medicine, University of Southern California, Los Angeles, CA 90089, USA.

${ }^{7}$ Norris Comprehensive Cancer Center, Keck School of Medicine, University of Southern California, Los Angeles, CA 90089, USA.

Received: 21 January 2020 Accepted: 2 August 2020

Published online: 15 August 2020

\section{References}

1. Wu JB, Shao C, Li X, Li Q, Hu P, Shi C, Li Y, Chen YT, Yin F, Liao CP, et al. Monoamine oxidase a mediates prostate tumorigenesis and cancer metastasis. J Clin Invest. 2014;124(7):2891-908.

2. Kushal S, Wang W, Vaikari VP, Kota R, Chen K, Yeh TS, Jhaveri N, Groshen SL, Olenyuk BZ, Chen TC, et al. Monoamine oxidase A (MAO A) inhibitors decrease glioma progression. Oncotarget. 2016;7(12):13842-53.

3. Li PC, Siddiqi IN, Mottok A, Loo EY, Wu CH, Cozen W, Steidl C, Shih JC. Monoamine oxidase a is highly expressed in classical Hodgkin lymphoma. J Pathol. 2017;243(2):220-9.

4. Bach AW, Lan NC, Johnson DL, Abell CW, Bembenek ME, Kwan SW, Seeburg $\mathrm{PH}$, Shih JC. CDNA cloning of human liver monoamine oxidase a and B: molecular basis of differences in enzymatic properties. Proc Natl Acad Sci U S A. 1988;85(13):4934-8.

5. Lan NC, Chen $\mathrm{CH}$, Shih JC. Expression of functional human monoamine oxidase a and B cDNAs in mammalian cells. J Neurochem. 1989;52(5): $1652-4$

6. Youdim MB, Edmondson D, Tipton KF. The therapeutic potential of monoamine oxidase inhibitors. Nat Rev Neurosci. 2006;7(4):295-309.

7. Weis SM, Cheresh DA. Tumor angiogenesis: molecular pathways and therapeutic targets. Nat Med. 2011;17(11):1359-70.

8. Davis ME. Glioblastoma: overview of disease and treatment. Clin J Oncol Nurs. 2016;20(5 Suppl):S2-8.

9. Stupp R, Mason WP, van den Bent MJ, Weller M, Fisher B, Taphoorn MJ, Belanger K, Brandes AA, Marosi C, Bogdahn U, et al. Radiotherapy plus concomitant and adjuvant temozolomide for glioblastoma. N Engl J Med. 2005;352(10):987-96.

10. Han F, Hu R, Yang H, Liu J, Sui J, Xiang X, Wang F, Chu L, Song S. PTEN gene mutations correlate to poor prognosis in glioma patients: a metaanalysis. OncoTargets and therapy. 2016:9:3485-92.

11. Sorrentino BP. Gene therapy to protect haematopoietic cells from cytotoxic cancer drugs. Nat Rev Cancer. 2002;2(6):431-41.

12. Dou R, Liu Z, Yuan X, Xiangfei D, Bai R, Bi Z, Yang P, Yang Y, Dong Y, Su W, et al. PAMs ameliorates the imiquimod-induced psoriasis-like skin disease in mice by inhibition of translocation of NF-kappaB and production of inflammatory cytokines. PLoS One. 2017;12(5):e0176823.

13. Eslami-Farsani M, Moslehi A, Hatami-Shahmir A. Allantoin improves histopathological evaluations in a rat model of gastritis. Physiol Int. 2018; 105(4):325-34

14. Hodorova I, Rybarova S, Vecanova J, Solar P, Domorakova I, Adamkov M Mihalik J. Comparison of expression pattern of monoamine oxidase a with histopathologic subtypes and tumour grade of renal cell carcinoma. Med Sci Monit. 2012;18(12):BR482-6. 
15. Jhaveri N, Cho H, Torres S, Wang W, Schonthal AH, Petasis NA, Louie SG, Hofman FM, Chen TC. Noscapine inhibits tumor growth in TMZ-resistant gliomas. Cancer Lett. 2011;312(2):245-52.

16. Wu JB, Lin TP, Gallagher JD, Kushal S, Chung LW, Zhau HE, Olenyuk BZ, Shih JC. Monoamine oxidase a inhibitor-near-infrared dye conjugate reduces prostate tumor growth. J Am Chem Soc. 2015;137(6):2366-74.

17. Conti A, Guli C, La Torre D, Tomasello C, Angileri FF, Aguennouz M. Role of inflammation and oxidative stress mediators in gliomas. Cancers. 2010;2(2): 693-712.

18. Landskron G, De la Fuente M, Thuwajit P, Thuwajit C, Hermoso MA. Chronic inflammation and cytokines in the tumor microenvironment. J Immunol Res. 2014;2014:149185.

19. Hanahan D, Weinberg RA. The hallmarks of cancer. Cell. 2000;100(1):57-70.

20. Gill JS, Zhu X, Moore MJ, Lu L, Yaszemski MJ, Windebank AJ. Effects of NFkappaB decoy oligonucleotides released from biodegradable polymer microparticles on a glioblastoma cell line. Biomaterials. 2002;23(13):2773-81.

21. Nagai S, Washiyama K, Kurimoto M, Takaku A, Endo S, Kumanishi T. Aberrant nuclear factor-kappaB activity and its participation in the growth of human malignant astrocytoma. J Neurosurg. 2002;96(5):909-17.

22. Zhen F, Song M, Liu Z, Zhou Y, Li D, Mao CQ. Antimicrobial effects and mechanisms of natural plant antimicrobial solution against Staphylococcus aureus. J Biol. 2015:31(4):50-4.

23. Yuan $X$, Qiu JY, Wang SY, Dou R, Xiangfei D, Yang P, Mao CQ. Inhibitory effects and preliminary molecular mechanisms of "natural plant antimicrobial solution" (PAMs) on liver cancer HepG2 cells. J Biol. 2019;36(4):26-9.

24. Zhou Y, Dou R, Bi Z, Yang Y, Liu Z, Wu Y, Qiu J, Wu C, Xiangfei D, Li D, Mao CQ Promotion of apoptosis in leukemia K562 cells by natural plant antimicrobial solution (PAMs). J China Pharmaceutical Univ. 2015;46(6):712-8.

25. Lessard L, Saad F, Le Page C, Diallo JS, Peant B, Delvoye N, Mes-Masson AM. NF-kappaB2 processing and p52 nuclear accumulation after androgenic stimulation of LNCaP prostate cancer cells. Cellular signaling. 2007;19(5): 1093-100.

26. Chen F, Yang D, Che X, Wang J, Li X, Zhang Z, Chen X, Song X. Livin mediates tumor cell invasion in the DU-145 cell line via NF-kappaB. Oncol Rep. 2012;27(6):2010-6.

27. Ren D, Yang Q, Dai Y, Guo W, Du H, Song L, Peng X. Oncogenic miR-210-3p promotes prostate cancer cell EMT and bone metastasis via NF-kappaB signaling pathway. Mol Cancer. 2017;16(1):117.

28. Zhang J, Kuang $Y$, Wang $Y, X u Q$, Ren Q. Notch-4 silencing inhibits prostate cancer growth and EMT via the NF-kappaB pathway. Apoptosis. 2017;22(6): $877-84$

\section{Publisher's Note}

Springer Nature remains neutral with regard to jurisdictional claims in published maps and institutional affiliations.

Ready to submit your research? Choose BMC and benefit from:

- fast, convenient online submission

- thorough peer review by experienced researchers in your field

- rapid publication on acceptance

- support for research data, including large and complex data types

- gold Open Access which fosters wider collaboration and increased citations

- maximum visibility for your research: over $100 \mathrm{M}$ website views per year

At $\mathrm{BMC}$, research is always in progress.

Learn more biomedcentral.com/submissions 